\title{
Optimization and Numerical Simulation of Novel Air-cooling System for the Thermal Management of Lithium-ion Battery Pack
}

\author{
Xiongchao Lin $^{1 *}$, Keke Shao ${ }^{1,2}$, Caihong Wang ${ }^{1}$ \\ ${ }^{1}$ School of Chemical \& Environmental Engineering, China University of Mining and Technology \\ (Beijing), D11 Xueyuan Road, Haidian District, Beijing 100083, P.R. China. \\ ${ }^{2}$ School of Mechanical Engineering, Beijing Institute of Technology, Zhongguancun South Street, \\ Haidian District, Beijing 100081, P.R.China \\ *E-mail: 1xc@cumtb.edu.cn
}

Received: 4 September 2021 / Accepted: 12 October 2021 / Published: 6 December 2021

\begin{abstract}
A thermal management system to cool the battery pack and control the operating temperature within a safe range is very essential for power battery. In this study, a staggered counterflow air-cooling structure was proposed to enhance the low heat transfer efficiency of air-cooling module in the lithium-ion battery and reduce the largely local temperature difference. The main factors (i.e., height of channel, velocity of air, and the number of channels) affecting the temperature distribution of cell were systematically investigated. Particularly, orthogonal test combined with single factor analysis method was used to optimize the thermal management system of lithium-ion battery. Such method could greatly reduce the number of tests and improve work efficiency. The results show that the maximum temperature $\left(T_{\max }\right)$ and maximum temperature difference ( $T_{\max }$, diff.) of the battery gradually decreased with the increase of the height of flow channels. Higher flow rate of the cooling medium could obviously reduce the $T_{\max }$ of the battery. The number of the flow channels presented insignificant effect on reducing the $T_{\max }$ of the battery. The optimized parameters were height at $4 \mathrm{~mm}$, velocity at $3 \mathrm{~m} / \mathrm{s}$ and number of channels at 6 . Under the optimized condition, the battery achieved a better temperature distribution with a minimum $T_{\max }$ and $T_{\max , \text { diff. }}$
\end{abstract}

Keywords: Air-cooling; Lithium-ion battery; Thermal management; Numerical simulation, orthogonal matrix

\section{$\underline{\text { FULL TEXT }}$}

(C) 2022 The Authors. Published by ESG (www.electrochemsci.org). This article is an open access article distributed under the terms and conditions of the Creative Commons Attribution license (http://creativecommons.org/licenses/by/4.0/). 